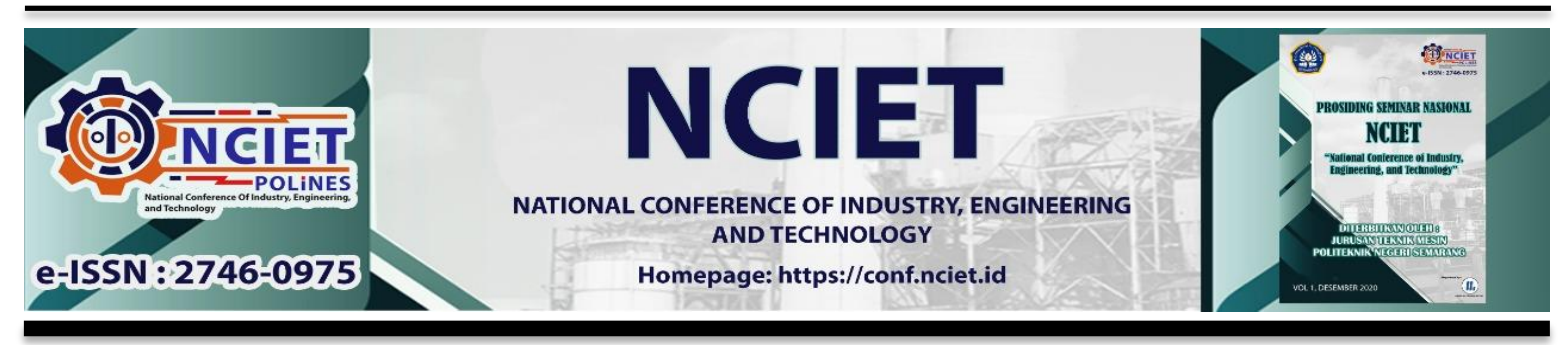

Prosiding Seminar Nasional NCIET Vol.1 (2020) B59-B66

$1^{\text {st }}$ National Conference of Industry, Engineering and Technology 2020,

Semarang, Indonesia.

\title{
RANCANG BANGUN SISTEM PENDINGIN MOTOR LISTRIK MENGGUNAKAN WATER JACKET LILITAN PIPA PIPIH
}

\author{
Rahmat Subarkah $^{1 *}$, Ghany Heryana ${ }^{2}$, Fitri Wijayanti ${ }^{1}$, Arifia Ekayuliana ${ }^{1}$, dan \\ Irwandi $^{1}$ \\ ${ }^{1}$ Jurusan Teknik Mesin, Politeknik Negeri Jakarta \\ J1. Prof. DR. G.A. Siwabessy, Kampus Universitas, Depok, 16425 \\ ${ }^{2}$ Jurusan Teknik Mesin, Sekolah Tinggi Wastukancana \\ Jl. Alternative Bukit Indah, Purwakarta, 41151 \\ *E-mail: rahmat.subarkah@mesin.pnj.ac.id
}

\begin{abstract}
Abstrak
Motor listrik semakin banyak digunakan dalam dunia industry. Penggunaan motor listrik memiliki keunggulan dalam banyak hal seperti bebas emisi dan tidak bising. Akan tetapi ada pula kelemahannya seperti meningkatnya tegangan thermal pada suhu tinggi. Di saat yang sama, dalam dunia industry motor listrik adalah peralatan yang paling banyak mengkonsumsi energ. Untuk itu sangat penting untuk dapat menjaga suhu motor listrik tetap rendah agar kerusakan akibat tegangan thermal tidak terjadi.

Penelitian ini adalah menjelaskan tahapan dalam rancang bangun system pendingin motor listrik menggunakan water jacket pipa pipih. Tahapan penelitian ini dimulai dengan membuat desai motor listrik yang dilanjutkan dengan merancang alat bantu produksi pipa pipih.

Proses manufaktur system pendingin ini dapat dilakukan menggunakan permesinan konvensional seperti mesin bubut, mesin bor dan mesin las listrik. Proses manufaktur diperlukan untuk membuat mandrel, casing motor listrik, alat pemipih pipa dan rig. Selain itu diperlukan peralatan yang sudah tersedia di pasar secara umum seperti radiator mobil, pompa air DC, elemen pemanas serta sumber arus listrik DC berupa baterai.

Selanjutnya peralatan dirangkai dengan menyambungkannya dengan selang untuk siklus air pendingin dan kabel untuk rangkaian elemen pemanas, kipas radiator dan pompa air DC. Peralatan dapat digunakan untuk melakukan pengujian.
\end{abstract}

Kata Kunci: : motor listrik; water jacket; pipa pipih; cooling electrical motor.

\section{PENDAHULUAN}

Motor listrik semakin banyak digunakan dalam dunia industry seperti pada pumpedstorage, pipeline compression dan propulsi kapal (Aliasand \& Josh, 2020). Saat ini motor listrik juga digunakan pada dunia transportasi seperti pada kendaraan mobil dan motor. Dengan semakin meningkatnya penggunaan motor listrik menjadikan Indonesia harus menjadi salah satu negara yang harus mampu memproduksi motor listrik. Terlebih lagi pemerintah Indonesia dalam PP No. 14 Tahun 2015 tentang Rencana Induk Pembangunan 
Industri Nasional Tahun 2015 -2035 telah mencanangkan penggerak mula motor listrik sebagai industry prioritas (Peraturan Pemerintah Republik Indonesia No. 14, Rencana Induk Pembangunan Industri Nasional Tahun 2015 -2035, 2015).

Penggunaan motor listrik memiliki keunggulan dalam banyak hal seperti bebas emisi dan tidak bising (Łapko, 2016). Akan tetapi ada pula kelemahannya seperti meningkatnya tegangan thermal pada suhu tinggi (Huai, Melnik, \& Thogersen, 2003). Di saat yang sama, dalam dunia industry motor listrik adalah peralatan yang paling banyak mengkonsumsi energi (Trianni, Cagno, \& Accordini, 2019). Untuk itu sangat penting untuk dapat menjaga suhu motor listrik tetap rendah agar kerusakan akibat tegangan thermal tidak terjadi.

Suhu operasi ideal motor listrik adalah berkisar $60-80^{\circ} \mathrm{C}$, akan tetapi pada kenyataannya dapat mencapai suhu $100^{\circ} \mathrm{C}$. Untuk itu diperlukan system pendingin yang dapat menurunkan suhu operasional hingga mencapai suhu optimal dari motor listrik.

Selama ini system pendingin motor listrik adalah menggunakan udara dengan bantuan sirip pada dinding casing motor listrik. Metode pendinginan seperti ini dinilai kurang efektif karena kemampuan udara dalam mendisipasi panas kurang baik. Selain itu, kelemahan penggunaan udara dalam pendingin motor listrik adalah membutuhkan ruang dan bobot yang lebih besar. Untuk mengatasi kekurangan tersebut diperlukan aliran fluida cair yang memiliki kemampuan disipasi panas yang baik, salah satunya adalah air.

Masalah yang muncul jika menggunakan air sebagai media pendingin adalah dapat menyebabkan hubungan pendek pada instalasi listrik pada lilitan motor. Diperlukan perangkat yang dapat dengan efektif menurunkan suhu operasional motor listrik dan juga mencegah terjadinya hubungan singkat dari arus listrik. Untuk itu diperlukan suatu penelitian pengembangan system pendingin motor listrik menggunakan water jacket dengan lilitan pipa pipih.

\section{METODE PENELITIAN}

Keseluruhan rancang bangun sistem pendingin motor listrik menggunakan water jacket lilitan pipa pipih diawali dengan mengasumsikan jumlah energy yang diubah menjadi panas oleh motor listrik dengan daya 7500 Watt. Dengan asumsi bahwa energy yang diubah menjadi panas sebesar $2 \%$ maka panas tersebut adalah sebesar 150 Watt. Jumlah panas inilah yang harus didinginkan dari motor listrik. Selanjutnya diperlukan peralatan system pendingin water jacket sebagai alat penelitian, maka yang pertama dilakukan pada penelitian 
ini adalah perancangan, persiapan dan pembuatan/konstruksi peralatan pendingin water jacket.

Proses pada tahapan ini adalah manufaktur peralatan pendingin motor listrik dengan memperhatikan parameter yang telah dihasilkan oleh simulasi Solidworks dan rancangan perhitungan teoritis.

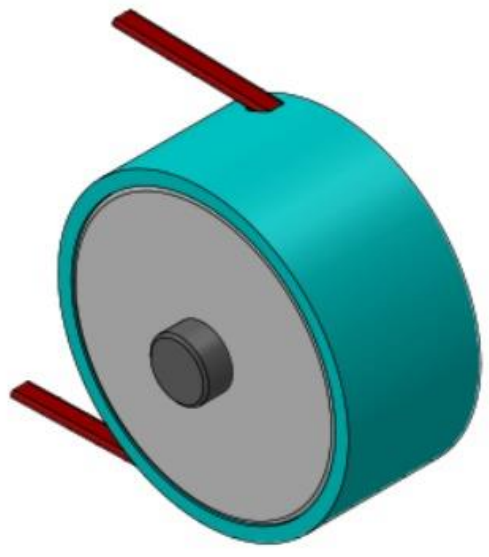

(a).

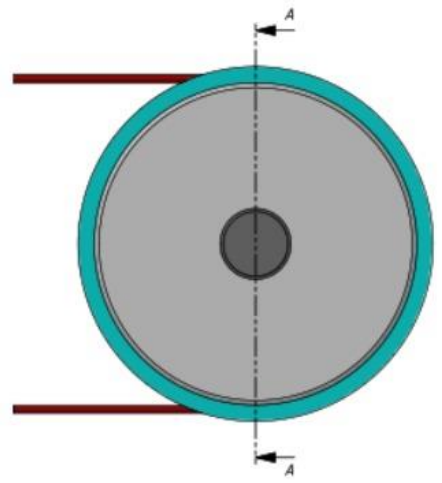

(b).

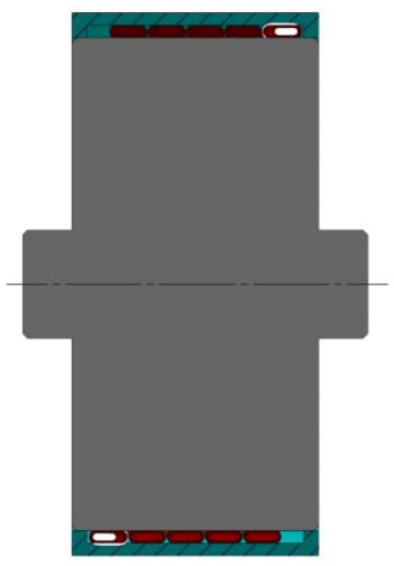

(c)

Gambar 1. Rancangan Water Jacket Pendingin Motor Listrik dengan Lilitan Pipa Pipih. (a) 3-D desain, (b) tampak depan, (c), potongan A-A

\section{HASIL DAN PEMBAHASAN}

Untuk mendapatkan hasil maksimal dalam proses pendinginan motor listrik, maka diperlukan informasi tentang motor listrik. Khususnya bagian dari motor listrik yang menghasilkan panas. Bagian ini yang akan menjadi focus penyerapan panas dari system pendingin.

Untuk keperluan pemipihan pipa kalor maka diperlukan mesin pemipih pipa dengan desain sebagai berikut:

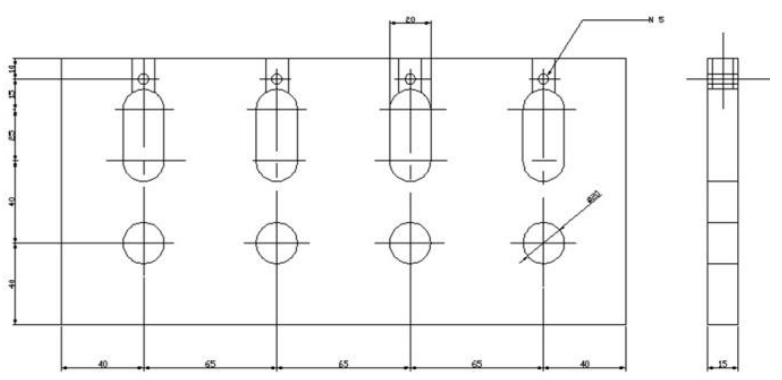




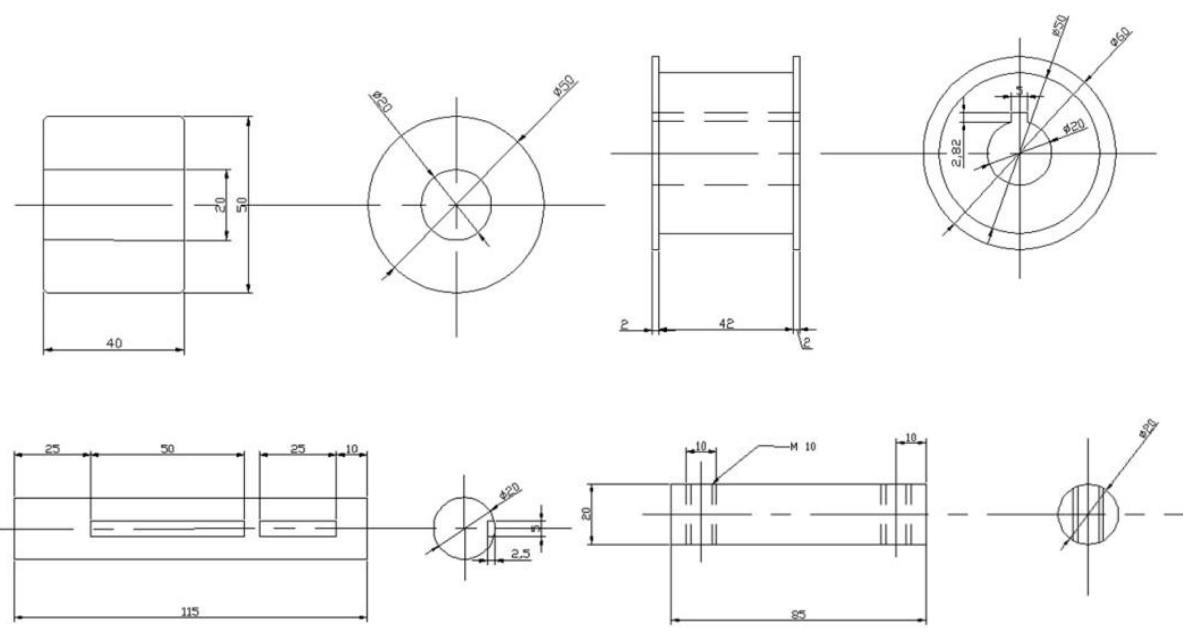

Gambar 2. Desain Mesin pemipih

Dari desain yang sudah ditentukan, lalu dilakukanlah proses manufaktur di workshop Jurusan Teknik Mesin Politeknik Negeri Jakarta.

Hasil dari proses pembuatan mesin pemipih terlihat pada gambar berikut ini:
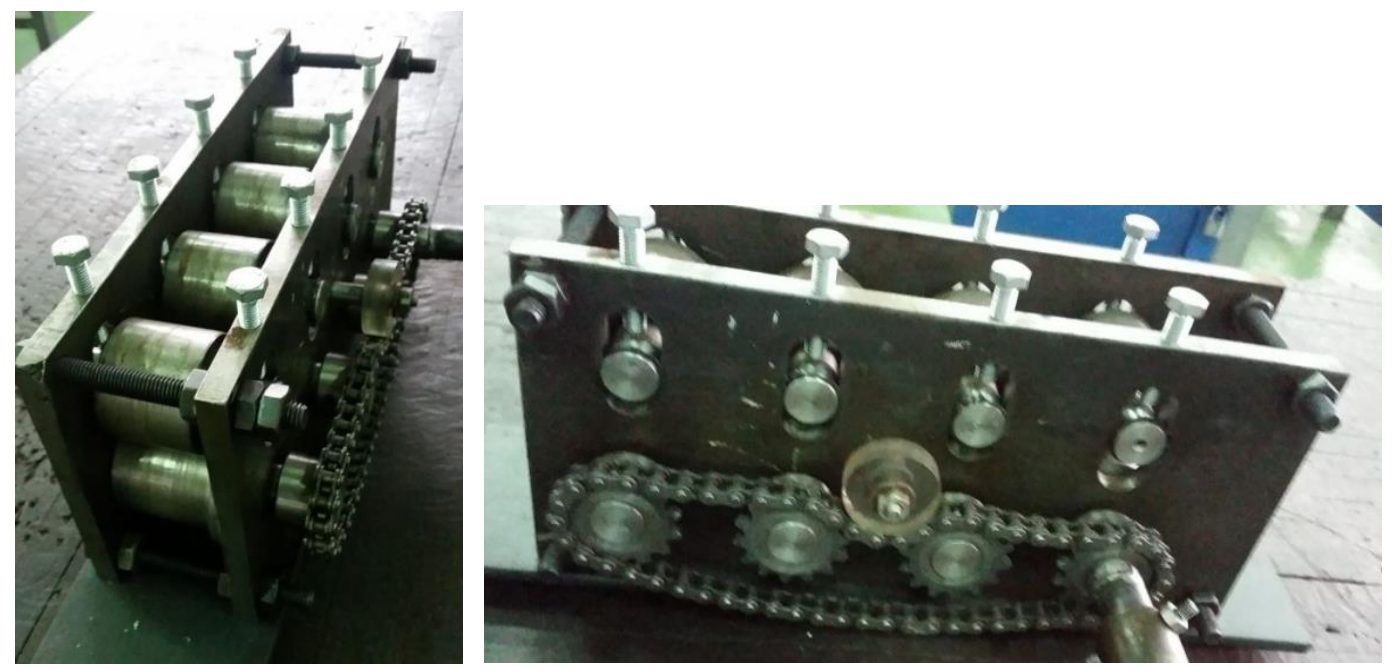

Gambar 3. Mesin pemipih

Menggunakan mesin roller yang sudah dibuat lalu dilakukan pemipihan pipa tembaga dengan diameter $1 / 2$ " menjadi ukuran pipih $7 \mathrm{~mm}$. Tujuan pemipihan ini adalah untuk memperbesar luas perpindahan panas.

Hasil dari pemipihan pipa seperti terlihat pada gambar berikut ini: 


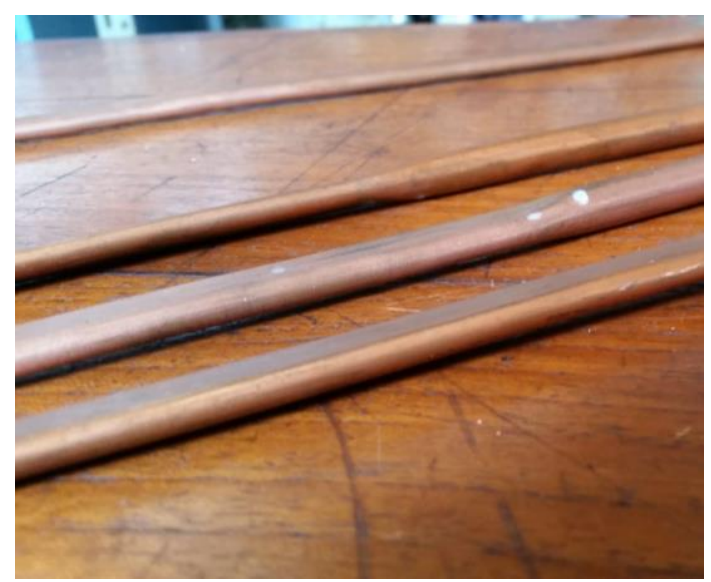

Gambar 4. Hasil pemipihan pipa

Mandrel diperlukan untuk sebagai alat bantu pada proses pekerjaan rolling. Manderel adalah sebuah silinder yang akan menjadi pola bagi diameter dalam dari sebuah pipi koil. Diameter luar mandrel adalah $310 \mathrm{~mm}$ yang merupakan diameter luar dari casing motor listrik.

Proses pembuatan mandrel menggunakan mesin bubut konvensional seperti terlihat pada gambar berikut ini:
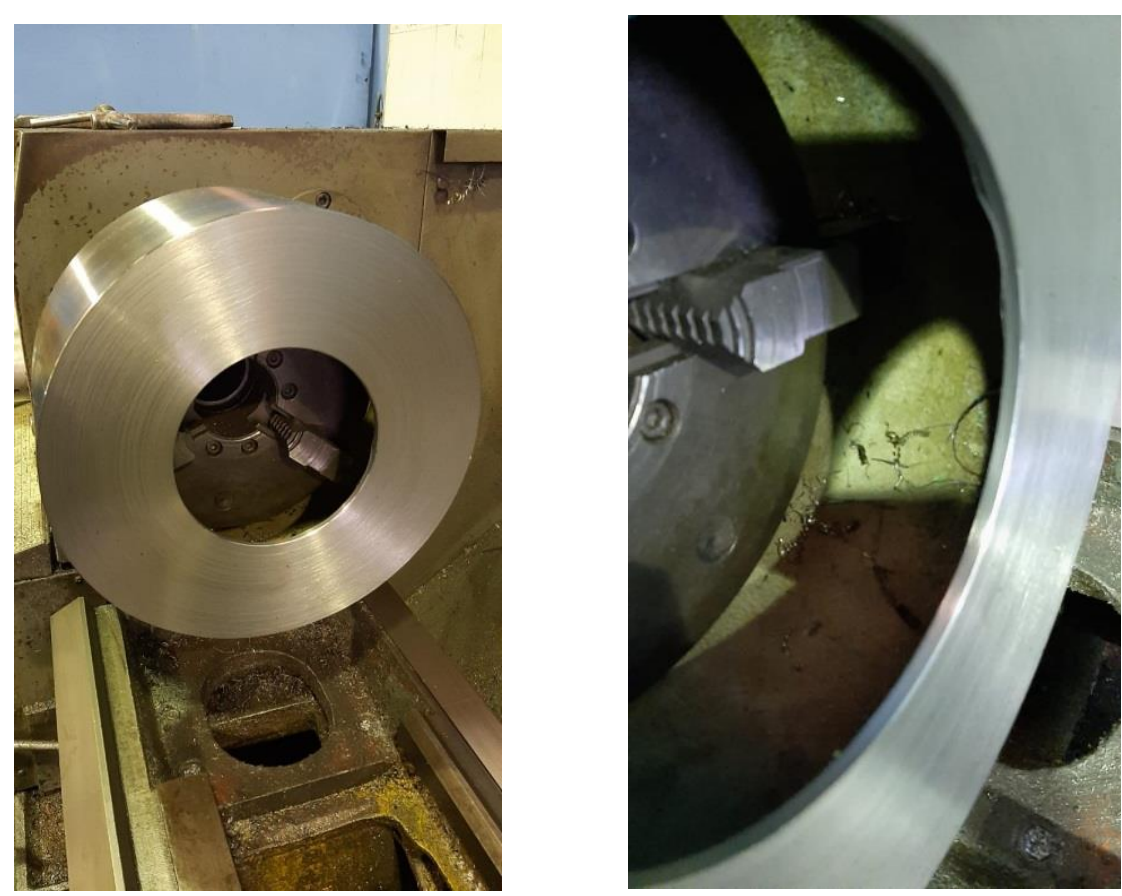

Gambar 5. Proses Permesinan Pembuatan Mandrel

Proses selanjutnya adalah rolling pipa pipih. Proses rolling menggunakan metode cold forming dengan memberikan tekanan pada pipa pipih mengikuti bentuk mandrell dengan diameter $310 \mathrm{~mm}$. Diameter ini menyesuaikan dengan diameter luar motor listrik. 
Diameter dalam roll pipa tersebut adalah $310 \mathrm{~mm}$ mengikuti ukuran luar dari motor listrik yang akan didinginkan. Pipa tembaga yang pada tahap sebelumnya sudah dipipihkan memiliki panjang $7 \mathrm{~m}$. Setelah di-rolling didapat 7 lilitan.

Proses ini diikuti dengan pengelasan pipa tembaga untuk menghindari back spring arah radial dan aksial serta menjadikan lilitan pipa terikat kuat antara satu dan lainnya.

Lilitan pipa tembaga pipih dapat dilihat pada gambar berikut ini:
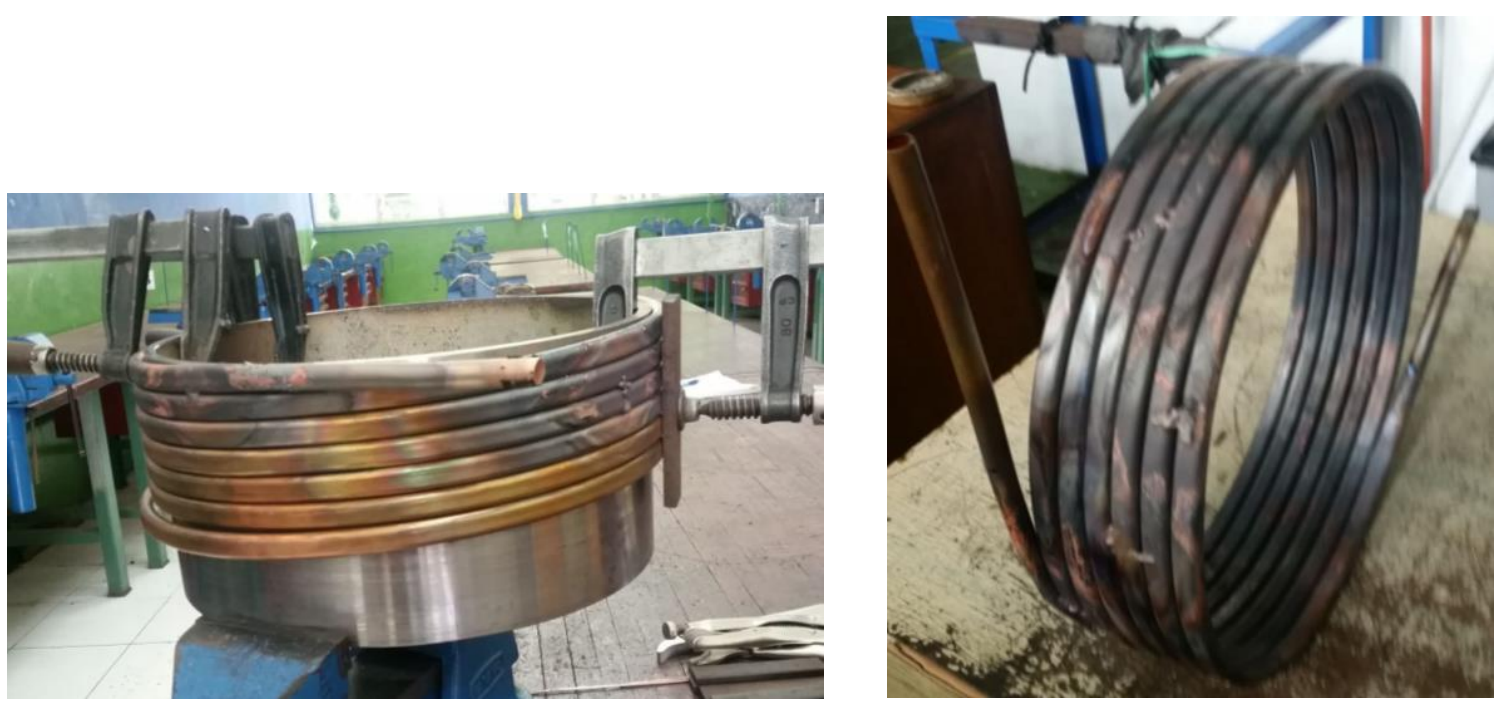

Gambar 6. Proses Pelilitan dan Pengelasan Pipa

Agar casing motor listrik dapat kokoh pada rig maka casing motor listrik harus dipasang secara kuat. Untuk itu diperlukan penahan yang dapat menyangga secara baik. Dua buah besi siku $5 \mathrm{~cm}$ digunakan untuk keperluan ini. Casing motor listrik diikat dengan dua buah baut pada sisi kiri dan kanan sedangkan penahan casing ini diikat dengan cara mengelas pada bagian dasar rig.

Peletakkan casing motor listrik pada penyangga seperti terlihat pada gambar berikut ini:

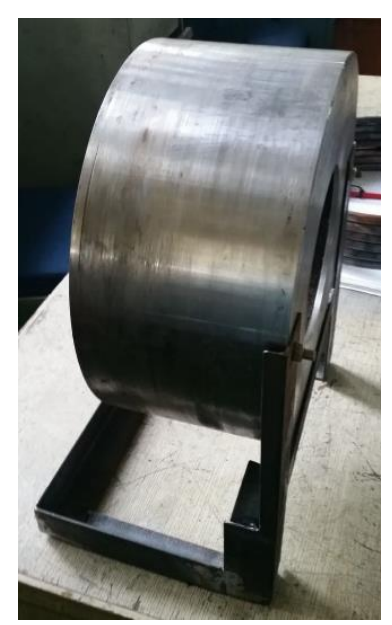

Gambar 7. Pemasangan casing motor listrik pada penyangga 
Lilitan pipa pipih digunakan dengan tujuan agar dapat menyerap panas yang dihasilkan oleh motor listrik. Pipa yang sudah dipipihkan dipasangkan pada casing motor listrik dengan suaian sesak agar dapat menyerap panas dari motor listrik secara maksimal.

Lilitan pipa pipih ini memeliki bagian inlet dan outlet air pendingin. Pemasangan lilitan pipa pipih ini juga harus memperhatikan posisi inlet dan outlet. Posisi inlet diletakkan pada bagian atas sejajar outlet dari radiator, sedangkan posisi outlet diletakkan pada bagian bawah sejajar inlet radiator. Hal ini dilakukan agar sirkulasi air pendingin dapat berjalan optimal dengan hambatan yang kecil.

Pemasangan lilitan pipa pipih pada casing motor listrik seperti terlihat pada gambar berikut ini:

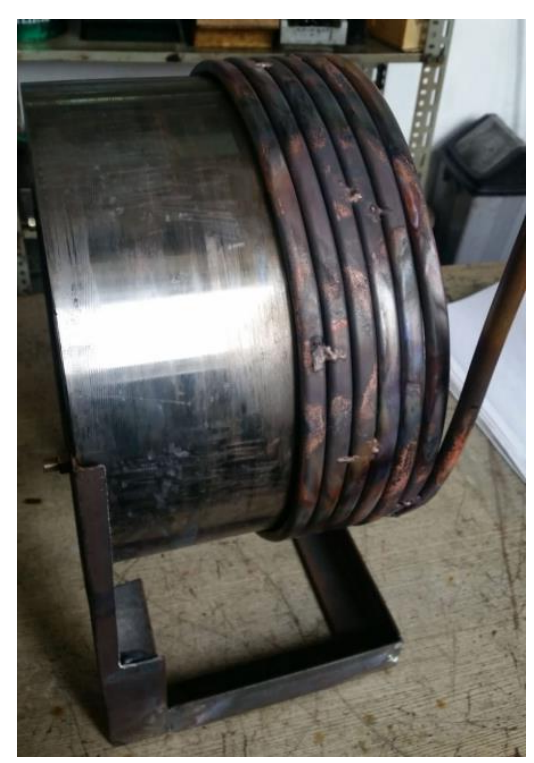

Gambar 8. Pemasangan lilitan pipa pipih pada casing motor listrik

Selanjutnya proses merangkai peralatan casing motor dan lilitan pipa pipih dengan komponen lain yang tidak perlu dilakukan proses permesinan seperti pompa air DC, radiator, kipas radiator, elemen pemanas dan baterai. Peralatan tersebut dirangkai dengan menghubungkannya dengan selang untuk sirkulasi air pendingin dan kabel untuk menghubungkan arus listrik.

\section{KESIMPULAN}

Dari review artikel didapatkan alternative desain system pendingin motor listrik yang ditindaklanjuti dengan pembuatan peralatan hingga siap untuk dilakukan pengujian. 
Dari proses permesinan yang dilakukan terlihat bahwa komponen penting berupa lilitan pipa pipih dan casing motor listrik dapat diproduksi dengan menggunakan peralatan permesinan konvensional yang ada di workshop Teknik Mesin Politeknik Negeri Jakarta.

Perlu dilakukan pekerjaan selanjutnya hingga analisa hasil penelitian dapat mengungkapkan karakteristik system pendingin motor listrik yang optimal.

\section{DAFTAR PUSTAKA}

Aliasand, A. E., \& Josh, F. T. (2020). Selection of Motor foran Electric Vehicle: A Review. Materials Today: Proceedings, 24, 1804-1815. https://doi.org/10.1016/j.matpr.2020.03.605

Huai, Y., Melnik, R. V. N., \& Thogersen, P. B. (2003). Computational analysis of temperature rise phenomena in electric induction motors. Applied Thermal Engineering, 23(7), 779-795. https://doi.org/10.1016/S1359-4311(03)00013-9

Łapko, A. (2016). The Use of Auxiliary Electric Motors in Boats and Sustainable Development of Nautical Tourism - Cost Analysis, the Advantages and Disadvantages of Applied Solutions. Transportation Research Procedia, 16(March), 323-328. https://doi.org/10.1016/j.trpro.2016.11.031

Peraturan Pemerintah Republik Indonesia No. 14, Rencana Induk Pembangunan Industri Nasional Tahun 2015 -2035. , (2015).

Trianni, A., Cagno, E., \& Accordini, D. (2019). A review of energy efficiency measures within electric motors systems. Energy Procedia, 158, 3346-3351. https://doi.org/10.1016/j.egypro.2019.01.964 